\title{
Los bienes del pasado
}

Jorge Benavides Solís | Escuela Técnica Superior de Arquitectura, Universidad de Sevilla

URL de la contribución <www.iaph.es/revistaph/index.php/revistaph/article/view/3892>

\section{0}

Los coordinadores del debate advierten a los posibles participantes: "Queremos caracterizar una manera contemporánea de mirar a los objetos del pasado"

1

Según la Real Academia Española (RAE) la palabra objeto tiene nueve acepciones. Solamente la sexta la define como "cosa", que también tiene igual número de acepciones. El plural, objetos, haría referencia tanto a las cosas como a la "materia de conocimiento o sensibilidad de parte del sujeto, incluso este mismo".

\section{2}

Lo contemporáneo vinculado al pasado no puede prescindir del futuro. Supone también una forma de concebir la historia, cuyo significado en origen fue inquirir, investigar, conocer. El significado actual proviene del latín a partir del siglo XIV: conocimiento de eventos pasados; pero, según Marx y a tenor del pensamiento de Benjamín, también con el futuro; de ahí el significado de revolución: "cambio rápido y profundo en cualquier cosa".

Hoy por hoy quizá posible solamente en el pensamiento (Onfray), en la ciencia (Kuhn) y en el arte (neo vanguardias) incluso bajo una concepción transdisciplinar; con visión holística y sistémica. No en la política. En arte quizá convenga diferenciar entre transgresión y revolución. En suma, la concepción occidental de la historia requiere de tres componentes indispensables: hechos, tiempo y protagonistas.

\section{3}

En oriente se acostumbra a realizar el registro de los hechos prescindiendo de cuándo sucedieron. Borges recordaba que los ingleses tuvieron mucha dificultad para escribir, bajo el prisma occidental, la primera historia de la India cuando fue su colonia.

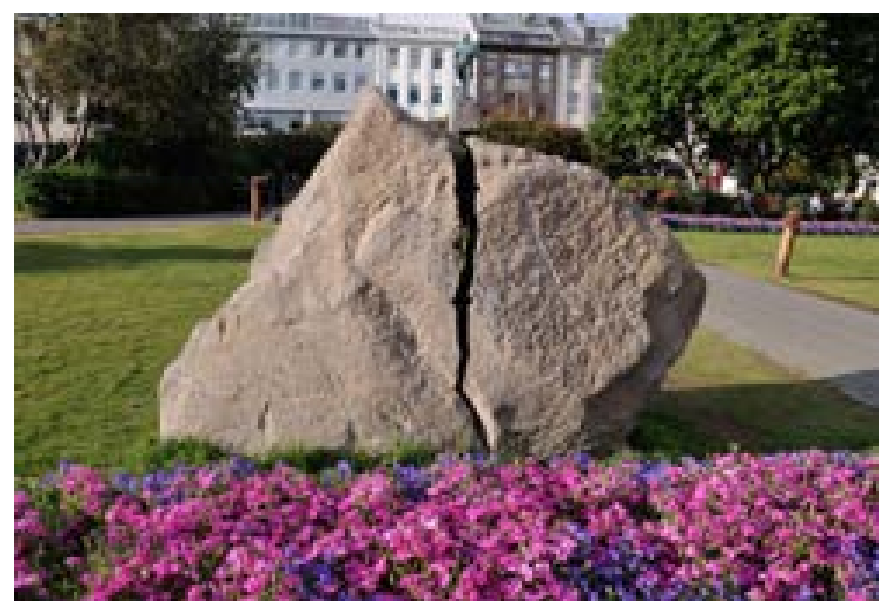

The Black Cone, monumento a la desobediencia civil. Reikiavik, Islandia. De Santiago Sierra | foto Philip Karstadt

\section{4}

El sapiens percibe los hechos o eventos con espacio y tiempo. Registra su experiencia como una relación con el entorno, entendido éste, en su más amplio significado: concreto y abstracto. Tangible e intangible.

Esta experiencia no pertenece al ámbito de la historia sino más bien al de la cultura, palabra que no tuvieron los griegos clásicos pero sí los romanos con relación al cultivo de la tierra. La forma francesa de cultura, couture -francés antiguo-, se ha desarrollado en su propio significado especializado, más tarde se convirtió en culture, palabra que en el siglo XV temprano pasó al inglés y desde entonces en Europa comenzó a usarse con el significado polisémico actual. El diccionario usual del castellano de 1817 añade a la palabra cultura otro significado además del relacionado con la agricultura.

\section{5}

Al hilo de lo dicho, existen razones suficientes para que los bienes hechos en el pasado, representativos de 
la evolución de un pueblo, la legalidad los haya legitimado primero como objetos (cosas) que constituían el patrimonio artístico, monumental y por lo tanto material; luego históricos (muebles e inmuebles) y solamente en el siglo XX como partes del patrimonio cultural: tangible e intangible y luego aún más: bienes culturales de valor excepcional, registrados por la UNESCO como patrimonio mundial, es decir de todos los sapiens. Utilizo esta última palabra para esquivar las discusiones gramaticales de "genero".

\section{6}

Pretendo diferenciar entre los bienes del pasado, que tienen una acepción vinculados a la cultura, de los objetos del pasado, que según G. Wajcman (El Objeto del siglo, 2001) están vinculados al arte y a la historia aunque él dice que, "no se trata (ría) de un 'trasto', de una 'cosa' al lado del camino como el yelmo o el hacha de Heidegger; es un objeto que pueda guardar memoria a través de sus rasgos, que a la vez pueda resistirse al olvido, a la ‘celebración y a la propaganda'”.

El poder mira los objetos del pasado de manera aislada o descontextualizada; desde el lado opuesto, sucede todo lo contrario.

\section{7}

El objeto con memoria en principio fue el monumento. Las dos palabras comparten la misma raíz y significado: Monumentum est quod memoriae servandae gratia existat (Digesto, 11.7.2.6. Ulp., 25 ad ed.). Es monumento lo que existe para conservar la memoria. En varias partes del Digesto se encuentran definiciones como esta y se insiste en la idea de que la finalidad del monumentum era preservar para la posteridad la memoria del difunto.

\section{8}

La memoria equivale a la resistencia contra el olvido, pero sometida al tiempo puede convertirse en ruina. Aquello que se pierde es el olvido contra el cual solamente puede el recuerdo. Mantener la memoria y proteger la ruina como una forma de construir el recuerdo seleccionando los olvidos es un proceso neurológico y por tanto individual, pero en términos amplios, también social, cultural y político.

\section{9}

La cultura es un producto, un bien social complejo, anónimo, ubicuo, ahistórico sometido a un proceso caracterizado que toma forma por acumulación espontánea. Complejo porque proviene de diferentes ámbitos interrelacionados. Anónimo porque solamente es posible a partir del grupo. Ubicuo porque tiene manifestaciones en todas las partes del mundo. Ahistórico porque depende solamente de los hechos, no de las fechas.

La cultura convertida o en tanto un bien colectivo es transmitido como herencia. La cultura es una con muchas expresiones o manifestaciones, por eso parecería más conveniente hablar de culturas (La interpretación de las culturas, C. Geertz, 2013). Ese es el sentido que tiene el patrimonio cultural de la humanidad. Proviene de la sociedad del sapiens; es una, pero, a la vez, diversa. Es precisamente la diversidad interrelacionada que caracteriza a la unidad. Incluso es el caso de las partículas elementales. Está en el ámbito de lo común.

\section{0}

El patrimonio es un conjunto de bienes familiares, generalmente raíces, que son de la titularidad de un jefe de familia, herencia, dote.

No basta mirar los objetos del pasado sino construir el recuerdo, el objeto cultural como herencia para ser enriquecida.

\section{1}

La manera de mirar los objetos del pasado bajo el prisma contemporáneo de la filosofía, del arte, o de la representación es una opción creativa e interpretativa sin duda transdisciplinar, más allá de la arquitectura, según Gramsci, la más reformable y "discutible" de las artes. 